No. $19-14$

\title{
Inflation Thresholds and Inattention
}

\author{
Anat Bracha and Jenny Tang
}

\begin{abstract}
:
Inflation expectations are key to economic activity, and in the current economic climate of a heated labor market, they are central to the policy debate. At the same time, a growing literature on inattention suggests that individuals, and therefore individual behavior, may not be sensitive to changes in inflation when it is low. This paper explores evidence of such inattention by constructing three different measures based on the University of Michigan's Survey of Consumers 1 -year ahead inflation expectations. Exploring inflation thresholds of 2, 3, and 4 percent, our findings are consistent with the inattention hypothesis.
\end{abstract}

Keywords: inattention, inflation expectations, Phillips curve

\section{JEL Classifications: D83, D84, E31, E71}

Anat Bracha and Jenny Tang are senior economists in the research department at the Federal Reserve Bank of Boston. Their respective email addresses are anat.bracha@bos.frb.org and jenny.tang@,bos.frb.org.

This paper presents preliminary analysis and results intended to stimulate discussion and critical comment. The views expressed herein are those of the authors and do not indicate concurrence by the Federal Reserve Bank of Boston, the principals of the Board of Governors, or the Federal Reserve System.

This paper, which may be revised, is available on the web site of the Federal Reserve Bank of Boston at http://www.bostonfed.org/economic/wp/aspx. 


\section{Introduction}

According to the Phillips curve, running a heated labor market with unemployment rates below the NAIRU incurs the risk of high inflation. While in recent years the Phillips curve seems to have flattened, with annual inflation remaining low at around 2 percent and U.S. unemployment at a historically low rate, the concern still remains that high inflation could quickly return.

Inflation expectations are known to be important for the inflation-unemployment relationship since Phelps (1967) and Friedman (1968). Further support for this view comes from recent papers by Coibion and Gorodnichenko (2018) and Doser et al. (2018). Both studies show that incorporating consumer inflation expectations, as measured by the University of Michigan's Survey of Consumers (MSC), delivers a stable inflation-unemployment relationship which best explains the flattening of the Phillips curve, including the recent missing (dis)inflation during the Great Recession.

Consumers' inflation expectations are therefore a key input to assessing the risks of higher inflation when unemployment is below the NAIRU. Many suggestions about how inflation expectations are formed have been made. Aside from the commonly assumed paradigm of full information rational expectations, some proposals include adaptive expectations and various models of learning about the inflation process that resemble adaptive expectations (Sargent 1994; Evans and Honkapohja 2001; Gaspar, Smets, and Vestin 2010; Malmendier and Nagel 2016). Another class of models are those that maintain rationality while relaxing the full information assumption. These include models of sticky information, noisy information, and rational inattention where individuals optimally choose their information sets (Lucas 1972; Mankiw and Reis 2002; Woodford 2003; Sims 2003; Maćkowiak and Wiederholt 2009; and the papers reviewed in Sims 2010, Veldkamp 2011, and Wiederholt 2010).

Especially intriguing, given the current environment of low inflation, is the idea of inattention. Rational inattention suggests that individuals have limited processing capacity, and therefore may optimally decide not to pay attention when more information confers very small benefits. Inattention has broad implications in macroeconomics, since beliefs about economic conditions are crucial for agents' decisions that drive macroeconomic outcomes. A lack of full information, whether or not this results from a rational choice, can generate persistence of variables and delayed responses to shocks (Mankiw and Reis 2002; Gorodnichenko 2008; Maćkowiak and Wiederholt 2015). Rational inattention generates variation in the extent of information frictions across states of the world and across economic variables (Sims 2003; Maćkowiak and Wiederholt 2009; Maćkowiak and Wiederholt 2015). In the context of price levels, inattention implies that individuals may not discriminate between 2, 2.5, and 3 percent inflation, which in turn, could explain the current episode of persistently low inflation and what appears to be a flattening of the Phillips curve. 
In spite of its importance in economics, direct evidence of the inattention hypothesis is scarce. ${ }^{1}$ This paper contributes to the literature by being one of the first to provide direct evidence of inattention in the context of inflation. We are aware of only two other studies that directly examine inattention. Coibion, Gorodnichenko, and Kumar (2018) find evidence in support of inattention in firms, while Cavallo, Cruces, and Perez-Truglia (2017) find evidence when comparing countries that have experienced bouts of high or low inflation. While these studies focus on cross-firm and cross-country predictions of rational inattention, our paper has the advantage of studying individual inattention within the United States over a long period of time and under different economic conditions. Specifically, we use the MSC to construct three measures of inattention to current inflation and find that individuals systematically pay less attention to inflation when inflation is low.

While we use three measures of inattention, our first measure of inattention is the most direct and is novel to the literature. This measure takes advantage of a specific response sequence, unique in revealing inattention to current inflation while not being confounded with individuals' ability to generate forecasts of future inflation from their knowledge of current conditions. In this way, it is both better suited for providing evidence to inform theories about inattention per se, and is distinct from measures of uncertainty about future inflation.

No matter what proxy for inattention that we use, the results point to lower attention when inflation rates are below 3 or 4 percent, consistent with other findings showing that in recent periods, aggregate inflation expectations have been less responsive to macroeconomic shocks (Pfajfar and Roberts 2018). To further explore whether inattention at low levels of inflation leads to a flatter Phillips curve, we examine two periods of low inflation-between 1958 and 1969 and between 1995 and 2018. In both periods, we find a flat relationship between inflation and unemployment when annual inflation is running below 3 or 4 percent. This evidence suggests that inattention may be one mechanism behind the currently weak relationship between labor market tightness and inflation.

\section{Data and Measures of Inattention}

This paper uses the MSC set of questions regarding 1-year ahead inflation expectations, as shown in Figure 1. Using the responses to these questions, we construct a few measures of inattention: (1) the share of individuals who responded that inflation would be the same and then, when probed further, did not know the current inflation rate, (2) the mean and median error in forecasting scaled by actual inflation, both as raw scaled errors and in absolute terms, and (3) the response to past forecasting errors in an inflation

\footnotetext{
${ }^{1}$ Indirect evidence is more readily available. One example includes studies showing that models featuring inattention better match aggregate moments and responses to shocks (Mankiw and Reis 2007; Maćkowiak and Wiederholt 2015). Another type comes from work showing that forecasts reflect incomplete responses to new information (Carroll 2003, Coibion and Gorodnichenko 2015a).
} 
expectations regression model with an error correction term. In this last measure, inattention implies a weak relationship between the correction term and inflation expectations. Each of these measures or regression specifications, and the corresponding hypothesis implied by inattention, is explained below.

\section{Inattention Measure I:}

For the first measure we calculate the share of individuals who responded "Stay the same" to question A12: "During the next 12 months, do you think that prices in general will go up, or go down, or stay where they are now?" Then when probed further in question A12a: "Do you mean that prices will go up at the same rate as now, or that prices in general will not go up during the next 12 months?," they responded "Go Up," only to admit they "Don't know" when responding to question A12b: "By about what percent do you expect prices to go up/down on the average, during the next 12 months?"

Individuals with such a response sequence-labeled in our measure as "Same-DK"- reveal that they have not paid attention to current inflation, since after indicating that they believe prices will go up during the next year at the same annual rate as today, when probed, they could not provide a number for what the current rate is and instead said they "Don't know." 2

The first inattention hypothesis: if inattention occurs at low levels of inflation, we would expect to observe a higher share of Same-DK responses at low levels of inflation.

\section{Inattention Measure II:}

The second measure of inattention reflects inflation expectations and is, by definition, based on individuals who gave numerical estimates for inflation over the next 12 months. Therefore, it is complementary to the first measure of inattention.

Specifically, we take an individual's inflation expectations and calculate the difference between that prediction and the realized inflation rate. One of our measures takes the average of these individual errors, scaled by actual inflation. We explore several versions of this type of measure: (1) the mean raw error (as described), (2) the median raw error, (3) the mean absolute error, and (4) the median absolute error. The results are similar no matter which version of this measure we use. In the following sections, our discussion emphasizes the scaled mean absolute error:

\footnotetext{
${ }^{2}$ Binder (2017) uses all the responses to question A12b, including the "Don't know" response, to construct a measure of inflation uncertainty based on whether the numerical responses are round numbers. We measure only the fraction of respondents who answered "Don't know" to question A12b after replying with "Stay the same" to question A12, as this discrepancy more directly indicates the respondent's inattention to current inflation conditions without being confounded with the individual's ability to form a forecast of future inflation based on his or her knowledge of current inflation.
} 


$$
\text { mean absolute error } \text { er-1 }=\frac{\sum_{i}\left|E_{t-1, i}\left(\pi_{t-1, t+11}\right)-\pi_{t-1, t+11}\right| / N}{\pi_{t-1, t+11}}
$$

where $E_{t-1, i}\left(\pi_{t-1, t+11}\right)$ is the expected inflation between $t-1$ and $t+11, \pi_{t-1, t+11}$ is the realized inflation rate between $t-1$ and $t+11$, and $i$ denotes an individual observation.

The second inattention hypothesis: if inattention occurs at lower levels of inflation, we would expect greater errors in expectations (relative to actual inflation) when inflation is low.

This hypothesis implies that if the mean absolute error, e.g., $\sum_{i}\left|E_{t-1, i}\left(\pi_{t-1, t+11}\right)-\pi_{t-1, t+11}\right| / N$, is positively related to the level of inflation, the increase in this mean error is less than proportional.

\section{Inattention Measure III:}

For the third measure, we use the MSC's median annual inflation expectation. In this exercise, we fit a model of inflation expectations formation, which includes the past inflation expectation and an error correction term (that is, the gap between past inflation expectation and realized inflation). Specifically, the model we fit is:

$$
E_{t-1}\left(\pi_{t, t+11}\right)=\alpha \underbrace{E_{t-13}\left(\pi_{t-12, t-1}\right)}_{\text {past expectations }}+\beta \underbrace{\left(E_{t-13}\left(\pi_{t-12, t-1}\right)-\pi_{t-12, t-1}\right)}_{\text {correction term }} .
$$

This specification is flexible, thus enabling the data to reveal the degree of stickiness in expectations and the responsiveness of expectations to information revealed in the correction term. For our purposes, the most interesting term is the correction term. A negative coefficient of the correction term would mean that individuals pay attention to the current inflation rate and correct for past errors; meaning that if their previous expectations were too high, they would revise their future expectations downwards, and vice versa. Finding an insignificant or very small coefficient $\beta$ would mean that individuals pay little attention to current inflation, since over- or under-shooting expectations in the past does not have much effect on forming current expectations.

The third inattention hypothesis: if inattention occurs at lower levels of inflation, we would expect the correction term to have a weaker association with inflation expectations when inflation is low. At high inflation rates, we would expect there to be a negative relationship.

\section{Results}

The results show that when inflation is higher, there are fewer instances of Same-DK responses, smaller errors in forecasting, and a greater correction of past mistakes in forecasting. These findings are consistent with all three of the inattention hypotheses, and provide direct evidence of this important 
behavioral pattern over a long time period in the United States. Below are further details about the results for each inattention measure.

Inattention Measures I \& II: Same-DK Responses and the Scaled Mean Absolute Error

We first examine a scatter plot of the share of Same-DK responses versus the actual inflation rate that was present between March 1982 and April 2018 - see Figure 2. The results show a clear negative relationship between the share of Same-DK responses and the inflation level.

We test the results shown in Figure 2 by regressing the share of Same-DK responses each month on a high inflation dummy variable, "High Inf". The dummy takes a value of 1 if inflation is higher than a given threshold, and we vary the thresholds from 2 to 4 percent. The results presented in Table 1 Panel A confirm the scatter plot pattern in Figure 2 - namely, that a higher share of Same-DK responses is observed at low levels of inflation, findings that are consistent with the first inattention hypothesis. It is interesting, however, that the magnitude of the dummy variable's coefficient is larger when the threshold for highinflation is 3 or 4 percent compared to 2 percent. The only difference in moving from a 2 percent to a 3 percent threshold comes from classifying periods when inflation is between 2 and 3 percent as periods of low, not high, inflation. The larger coefficient, along with a similar constant across the two specifications, suggests that in periods when inflation is in the 2-3 percent range, individuals are as inattentive as they are during periods when inflation is below 2 percent. It is during the periods when inflation is over 3 percent that we observe a much lower share of Same-DK responses.

The scaled mean absolute error is composed of the mean absolute error term and the actual inflation rate. While the mean absolute error (not scaled by inflation) is higher in periods of relatively high inflation, such as in the late 1970s and the 1980s, the increase is less than proportional and the scaled errors during times of high inflation seem to be lower compared with the scaled errors during periods of low inflation (figure not provided). The results shown in Table 1 Panel B confirm this finding: on average, the scaled mean absolute error in inflation forecasting is lower in times of high inflation and is higher in times of low inflation. This relationship is reflected in the highly significant negative coefficient on the dummy variable that takes a value of 1 for periods of inflation above a certain threshold. The threshold varies from 2 to 4 percent, and we find consistent results throughout all the variations of the regression exercise. These results also hold when we control for inflation volatility or regress these two inattention measures on the level of inflation rather than on a dummy variable for high inflation periods (results available upon request), or if we use the other variants for measuring the forecasting error (see Online Appendix Tables A1-A3). 
Inattention Measure III: Response of Inflation Expectations to Past Forecasting Errors in the Period from January 1978 to April 2018

Our third measure tests for responsiveness in expectations by fitting a model of inflation expectations formation. The model we fit is:

$$
E_{t-1}\left(\pi_{t, t+11}\right)=\alpha \underbrace{E_{t-13}\left(\pi_{t-12, t-1}\right)}_{\text {past expectations }}+\beta \underbrace{\left(E_{t-13}\left(\pi_{t-12, t-1}\right)-\pi_{t-12, t}\right)}_{\text {correction term }}
$$

where $E_{t-1}\left(\pi_{t, t+11}\right)$ is the median expectation for inflation occurring between $t-1$ and $t+11$ (that is,over the next 12 months). The idea is that if individuals pay attention to inflation, they would learn from past forecasting mistakes and would correct their current inflation expectations based on the gap between last year's median expectation and the realized inflation rate. The third inattention hypothesis holds that there should be a significant negative relationship between the correction term and inflation expectations that becomes weaker at low levels of inflation.

To test this hypothesis, and whether the relationship is systematically different depending on whether the period is characterized by high or low inflation, we ran this regression separately for high and low inflation regimes. We again consider different high-inflation thresholds, ranging from 2 to 4 percent. As shown in Table 2, we find a negative and significant relationship between the correction term and median inflation expectations during high-inflation regimes, but not during low-inflation regimes. This difference is statistically significant, as shown in the results for the combined full-sample regression that includes interactions with the high-inflation dummy. This difference also holds if we include controls for recent changes in actual inflation and conduct panel regressions using individual-level responses (results available upon request).

Our estimates of $\beta$ are related to the estimates in Coibion and Gorodnichenko (2015a), which documented a slow response of forecasts (in the form of a forecast error) to information about inflation that is consistent with a noisy information model. We show that these responses are especially attenuated in periods of low inflation.

\section{Discussion}

Using very different measures, we find evidence consistent with inattention at low levels of inflation below 2-4 percent: higher share of Same-DK responses, large scaled errors in forecasting, and weaker responses to errors in past predictions. In the regression analysis, we find consistent negative and significant relationships for high-inflation regimes between the correction term and median inflation expectation that are not present during lower inflation regimes. 
To make sure that the results are not driven by the Great Recession, characterized by very low inflation and well-anchored long-run expectations, we run regressions on a period the omits the last 15 years (2003 to 2018), but still find a similar pattern of results. Namely, in high inflation periods, on average there is a significantly lower share of Same-DK responses and scaled errors in high inflation periods, as well as a negative and significant coefficient on the error correction term in the inflation expectation regression model that exists only in high inflation periods. When excluding the past 15 years, we also find that there is no significant relationship between the error correction term and inflation expectations when inflation is low. The results are provided in the Online Appendix, Tables B1-B3.

An interesting explanation for this consistent pattern of results may be that the effect is driven by individuals who were in their prime (25 to 54 years of age) during the high inflation period that occurred between 1969 and 1983. Perhaps these individuals, having experienced an episode of high inflation, consider an annual inflation rate that is under 3 percent to be low and not attention-worthy, while younger cohorts pay attention when inflation is 3 percent or less. Similarly, one may wonder if the results are driven by current prime-age individuals who have only experienced low inflation, and do not realize that the inflation rate is an important measure for them to follow. Such explanations would be consistent with recent studies highlighting the importance of personal experience in long-term beliefs and behavior (Malmendier and Nagel 2011, 2016; Malmendier and Shen 2018). To explore these two questions, we examine the SameDK share and the scaled mean absolute error measures that result when only considering individuals who were in their prime during the 1969-1983 high inflation period, and when only considering individuals who were in their prime when the MSC was conducted. The results are robust to excluding these populationssee Online Appendix Tables $\mathrm{C} 1-\mathrm{C} 4$ - and suggest that the pattern documented in this paper is not driven by the experience of a specific cohort.

There are some caveats to the analysis: we use proxies of inattention that may be subject to criticism. We discuss these possible challenges below.

Potential Criticism of the Same-DK Measure: One can argue that the Same-DK response reflects frustration with the question and is not indicative of inattention. One may also object to this measure since the share of such responses is low. While it is never possible to know what determines an individual's responses, the sequence of the Same-DK response is the closest that we can get to a direct measure of inattention, i.e., people revealing that they do not know the current level of inflation. This is also the reason that it is worthwhile exploring this measure even if Same-DK responses are not very common in the MSC. Moreover, if one believes that this response sequence is just noise, given that it is uncommon, then we should not find a systematic change in the relationship between this response share and the inflation level. Nevertheless, we do find such evidence. 
What about the Other "Don't Know" Responses? Why not examine the DK response to the first question (A12) asking about price level in general? The reason is that such DK responses confound inattention with an inability to form firm inflation expectations. A DK response to the first question about future prices in general could arise because the respondent is inattentive or because she is very attentive yet confused by different signals. For instance, the respondent may predict a decline in the price of oil, say due to a new extraction technology, yet at the same time expect that prices of imported consumer goods will increase due to the trade war with China. As a result, the respondent may be quite uncertain whether overall prices should be expected to increase or decrease during the coming year and hence may give a DK response despite being quite attentive to inflation and the factors driving it. Using the "Same-DK" sequence eliminates such concerns.

Potential Criticism of Using the Scaled Mean Error or the Scaled Median Error: A possible objection to using these measures is that the results they generate are driven by a few episodes of large errors, such as the Great Recession. Another objection is that errors do not necessarily reflect inattention. Rather, forecast errors may signal that individuals do not have a good model of the world.

The first objection is addressed by examining the results obtained by using the scaled mean error or scaled median error for a period that excludes the past 15 years, as well as conducting the analysis for periods with a limited raw error size of \pm 2 percent or a limited scaled error size of \pm 1.5 percent. We also conducted an analysis that excluded the first 10 years of the sample with high inflation (up to December 1987). All of these robustness checks yield the same qualitative results, refuting such concerns. The results are presented in the Online Appendix Tables D1-D3 (for limited error sizes of \pm 2 percent), Tables E1-E3 (for limited scaled error sizes of \pm 1.5 percent), and Tables F1-F3 (excluding all periods of high inflation up to December 1987).

The second objection is interesting. Does having an incorrect model of the economy, or being puzzled by the realized inflation, differ from inattention? Perhaps. Yet, if one is more puzzled systematically in times of low inflation compared with times of high inflation, this may be in and of itself a form of inattention, as one does not bother to update or construct a new model that fits the low inflation environment.

\section{Concluding Remarks}

Given that we find consistent results across three different proxies for inattention — using the share of those who responded Same-DK, errors in predictions among those who gave their numerical inflation estimates, and fitting an inflation expectations model on the aggregate-we conclude that consumer inflation expectations are insensitive to actual inflation when annual inflation rates are below 2-4 percent. 
The implication that individuals are insensitive to actual inflation when it is in the vicinity of the 2 percent annual level, as is the case today in the United States, is that the current risk of higher inflation, despite the unemployment rate being at a low level, is limited. To the extent that individuals act according to their expectations - and that at low levels of inflation of around 2 percent, inflation expectations are insensitive to new information - consumption decisions and wage negotiations should also be less affected by current economic conditions, which help to reduce inflation pressure. Furthermore, given that MSC inflation expectations have been shown to best explain realized inflation and lead to a stable inflationunemployment relationship, both before and after the Great Recession (see for example Coibion and Gorodnichenko 2015b; Coibion, Gorodnichenko, and Kamdar 2018, and Doser et al. 2018), consumers' inflation expectations may best reflect firms' inflation expectations. Indeed, this point has been argued by Kumar et al. (2015), who suggest that firm managers form expectations based on their individual shopping experiences. Hence, the insensitivity of consumer expectations at times of low inflation suggest, in essence, a flatter Phillips curve relationship between labor market tightness and inflation, which has puzzled policy makers recently.

An important question going forward is whether the flattening of the Phillips curve is the new norm, perhaps due to millennials, having grown to adulthood in a period characterized by low inflation, being different from past generations who have experienced high inflation. The analysis we conducted suggests that this is not the case. Excluding the past 15 years from the analysis and examining adults who were in their prime during the high inflation period between 1969 and 1983 yields similar results. We also examine the relationship between the share of Same-DK responses and inflation rates by selected years in Figure 2. Using different colors, the figure identifies pre-1993 survey responses, and survey responses obtained during three subsequent periods: 1993-2003, 2003-2008, and 2009-2018. It is clear that individuals surveyed in the late 1990s/early 2000s, when annual inflation was low, are not different from individuals surveyed more recently. If this time is not different, it implies that the Phillips curve was flatter during earlier periods of low inflation. This relationship is exactly what we find. Figure 3 plots annual inflation (measured by the core Consumer Price Index) against the unemployment rate between 1958 and 1969, a period characterized by low inflation, and more recently, the period between 1995 and 2018. The points when inflation is at or below 3 percent appear in black. In both time periods, the Phillips curve is flatter when inflation is below 3 percent. The same pattern holds when we look at annual inflation rates below 4 percent. Interestingly, between these two episodes of prolonged low inflation - that is, between 1970 and 1994 - there were several episodes of high inflation and then the negative expected Phillips curve relationship re-emerged. If we can learn from history, it suggests that the Phillips curve is flat at levels of inflation of up to 4 percent, a point at which individuals (and perhaps business owners also) do not pay much attention. However, there is reason to caution against such complacency, since if annual inflation 
goes above 4 percent, we should expect the Phillips curve to return to its larger negative slope, which would then accelerate the rise of inflation.

From a behavioral perspective, perhaps it is not surprising to find insensitivity to the inflation rate when it is low. Psychologists have documented that individuals are insensitive to small changes, a response that is often called Weber's Law. The law was originally documented in the nineteenth century using visual stimuli and weight sensations - for instance, lifting a 10 pound box may not feel different from lifting an 11 or 12 pound box, but lifting a 15 or 20 pound box will be perceived differently (Weber 1846). The law suggests the threshold of a "Just Noticeable Difference" (jnd), above which humans sense change, is proportional to the initial stimuli (the initial weight of the box). Applying this insight to a numeric setting, such as perceptions of the price level, it means that individuals are insensitive to small changes in prices up to a certain threshold that is proportional to the initial price level - that is, individuals are insensitive to inflation up to a certain rate threshold. Some authors have found mixed results for the jnd in inflation expectations using different methods and different survey instruments (see, for example, Henzel and Wollmershauser 2005, and earlier work by Batchelor 1986). Our results are consistent with the jnd, implying that a fresh look at the jnd directly may be worthwhile in our efforts to understand inflation expectations. 


\section{References}

Batchelor, R.A., 1986. “The Psychophysics of Inflation.” Journal of Economic Psychology 7(3): 269-290.

Binder, Carola. C. 2017. "Measuring Uncertainty Based on Rounding: New Method and Application to Inflation Expectations." Journal of Monetary Economics 90(October): 1-12.

Carroll, Christopher D. 2003. "Macroeconomic Expectations of Households and Professional Forecasters." Quarterly Journal of Economics 118(1): 269-298.

Cavallo, Alberto, Guillermo Cruces, and Ricardo Perez-Truglia. 2017. "Inflation Expectations, Learning, and Supermarket Prices: Evidence from Survey Experiments." American Economic Journal: Macroeconomics 9(3): 1-35.

Coibion, Olivier, and Yuriy Gorodnichenko. 2015a. "Information Rigidity and the Expectations Formation Process: A Simple Framework and New Facts.” American Economic Review 105(8): 2644-2678.

Coibion, Olivier, and Yuriy Gorodnichenko. 2015b. "Is the Phillips Curve Alive and Well after All? Inflation Expectations and the Missing Disinflation." American Economic Journal: Macroeconomics 7(1): 197-232.

Coibion, Olivier, Yuriy Gorodnichenko, and Rupal Kamdar. 2018. "The Formation of Expectations, Inflation, and the Phillips Curve.” Journal of Economic Literature 56(4): 1447-1491.

Coibion, Olivier, Yuriy Gorodnichenko, and Saten Kumar. 2018. "How Do Firms Form Their Expectations? New Survey Evidence.” American Economic Review 108(9): 2671-2713.

Doser, Alexander, Ricardo Nunes, Nikhil Rao, and Viacheslav Sheremirov. 2018. "Inflation Expectations and Nonlinearities in the Phillips Curve." School of Economics Discussion Papers 1018, School of Economics, University of Surrey.

Evans, George W., and Seppo Honkapohja. 2001. Learning and Expectations in Macroeconomics. Princeton, NJ: Princeton University Press.

Friedman, Milton. 1968. "The Role of Monetary Policy." American Economic Review 58(1):1-17.

Gaspar, Vitor, Frank Smets, and David Vestin. 2010. "Inflation Expectations, Adaptive Learning and Optimal Monetary Policy.” In Handbook of Monetary Economics, Vol. 3, edited by Benjamin M. Friedman and Michael Woodford, 1055-1095. Amsterdam: Elsevier.

Gorodnichenko, Yuriy. 2008. "Endogenous Information, Menu Costs and Inflation Persistence.” Working Paper No. 14184. Cambridge, MA: National Bureau of Economic Research.

Henzel, Steffen, and Timo Wollmershäuser. 2005. "Quantifying Inflation Expectations with the CarlsonParkin Method: A Survey-based Determination of the Just Noticeable Difference." Journal of Business Cycle Measurement and Analysis 2(3):321-352.

Kumar, Saten, Hassan Afrouzi, Olivier Coibion, and Yuriy Gorodnichenko. 2015. "Inflation Targeting Does Not Anchor Inflation Expectations: Evidence from Firms in New Zealand." Brookings Papers on Economic Activity (Fall): 151-208. 
Lucas, Robert E., Jr. 1972. "Expectations and the Neutrality of Money.” Journal of Economic Theory 4(2): $103-124$.

Maćkowiak, Bartosz, and Mirko Wiederholt. 2009. "Optimal Sticky Prices under Rational Inattention.” American Economic Review 99(3): 769-803.

Maćkowiak, Bartosz, and Mirko Wiederholt. 2015. "Business Cycle Dynamics under Rational Inattention." e Review of Economic Studies 82(4): 1502-1532.

Malmendier, Ulrike, and Stefan Nagel. 2011. "Depression Babies: Do Macroeconomic Experiences Affect Risk Taking?” Quarterly Journal of Economics 126(1): 373-416.

Malmendier, Ulrike, and Stefan Nagel. 2016. "Learning from Inflation Experiences." Quarterly Journal of Economics 131(1): 53-87.

Malmendier, Ulrike, and Leslie Sheng Shen. 2018. "Scarred Consumption.” Working Paper No. 24696. Cambridge, MA: National Bureau of Economic Research.

Mankiw, N. Gregory, and Ricardo Reis. 2002. "Sticky Information versus Sticky Prices: A Proposal to Replace the New Keynesian Phillips Curve.” Quarterly Journal of Economics 117(4): 1295-1328.

Mankiw, N. Gregory, and Ricardo Reis. 2007. "Sticky Information in General Equilibrium." Journal of the European Economic Association, 5(2-3): 603-613.

Pfajfar, Damjan, and John M. Roberts. 2018. "The Role of Expectations in Changed Inflation Dynamics." Finance and Economics Discussion Series 2018-062. Washington: Board of Governors of the Federal Reserve System.

Phelps, Edmund S. 1967. "Phillips Curves, Expectations of Inflation and Optimal Unemployment Over Time." Economica, 34(135): 254-281.

Sargent, Thomas J. 1994. Bounded Rationality in Macroeconomics. New York: Oxford University Press.

Sims, Christopher A. 2003. "Implications of Rational Inattention.” Journal of Monetary Economics 50(3): 665-690.

Sims, Christopher A. 2010. "Rational Inattention and Monetary Economics." In Handbook of Monetary Economics Vol. 3, edited by Benjamin M. Friedman, and and Michael Woodford, , 155-181. Amsterdam: Elsevier.

Veldkamp, Laura L. 2011. Information Choice in Macroeconomics and Finance. Princeton, NJ: Princeton University Press.

Weber, E. H., 1846. "Der Tastsinn und das Gemeingefühl.” In R. Wagner (ed.), Handworterbuch der Physiologie, Vol. 3. Braunschweig: Vieweg.

Wiederholt, Mirko. 2010. "Rational Inattention.” In The New Palgrave Dictionary of Economics, Living Edition, edited by Palgrave Macmillan. London: Palgrave Macmillan. https://doi.org/10.1057/978-1-34995121-5_2901-1. 
Woodford, Michael. 2003. "Imperfect Common Knowledge and the Effects of Monetary Policy." In Knowledge, Information, and Expectations in Modern Macroeconomics: In Honor of Edmund S. Phelps, edited by Philippe Aghion, Roman Frydman, Joseph Stiglitz, and Michael Woodford, 25-58. Princeton, NJ: Princeton University Press. 
Figure 1: 1-Year Ahead Michigan Survey of Consumers Inflation Expectation Questions

A12. During the next 12 months, do you think that prices in general will go up, or go down, or stay where they are now?

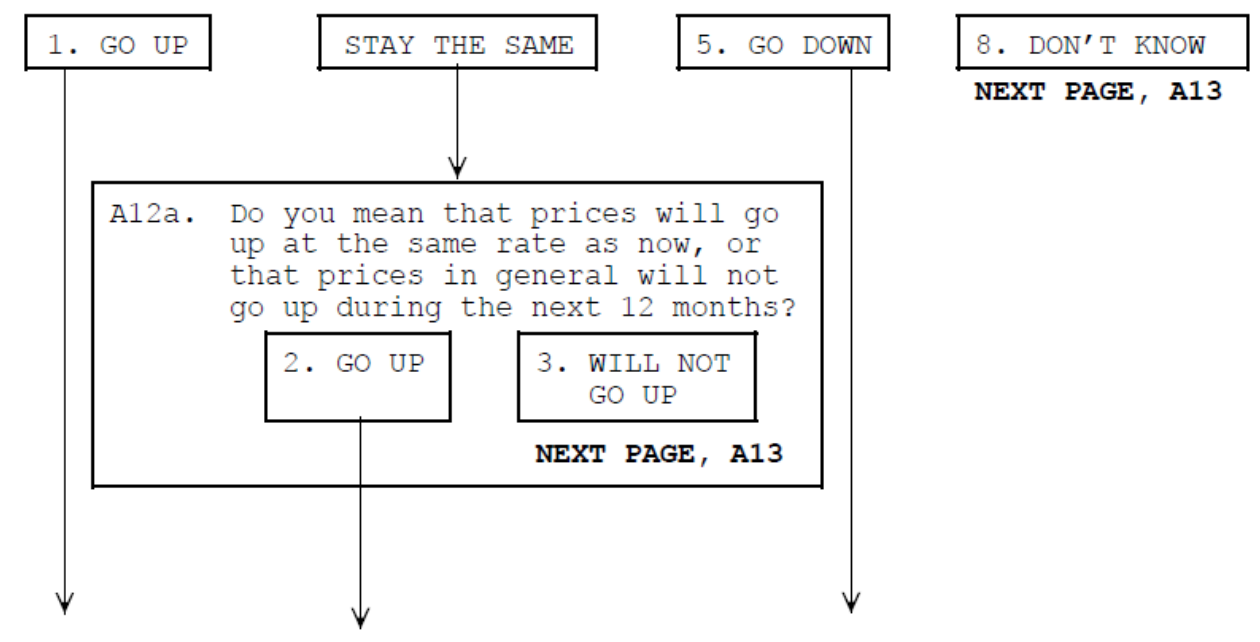

$\mathrm{A} 12 \mathrm{~b}$. By about what percent do you expect prices to go

(up/down) on the average, during the next 12 months?

(USE PROBE BELOW IF ANSWER IS GREATER THAN 5\%)

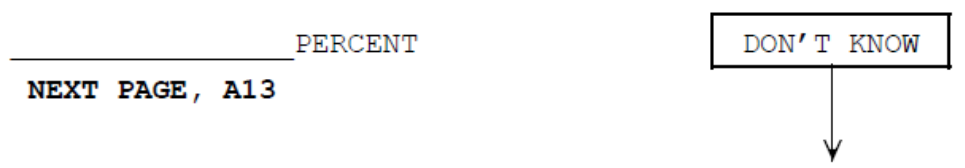

A12C. (AFTER A DON'T KNOW RESPONSE IS PROBED, IF R SAYS,

"I DON'T KNOW", USE THE FOLLOWING PROBE:)

(USE PROBE BELOW IF ANSWER IS GREATER THAN 5\%)

How many cents on the dollar do you expect prices

to go (up/down) on the average, during the next 12

months?

CENTS ON DOLLAR

98. $\mathrm{DON}^{\prime} \mathrm{T}$ KNOW 
Figure 2: Share of Same-DK Responses versus Actual Inflation Rates, 1982 to 2018

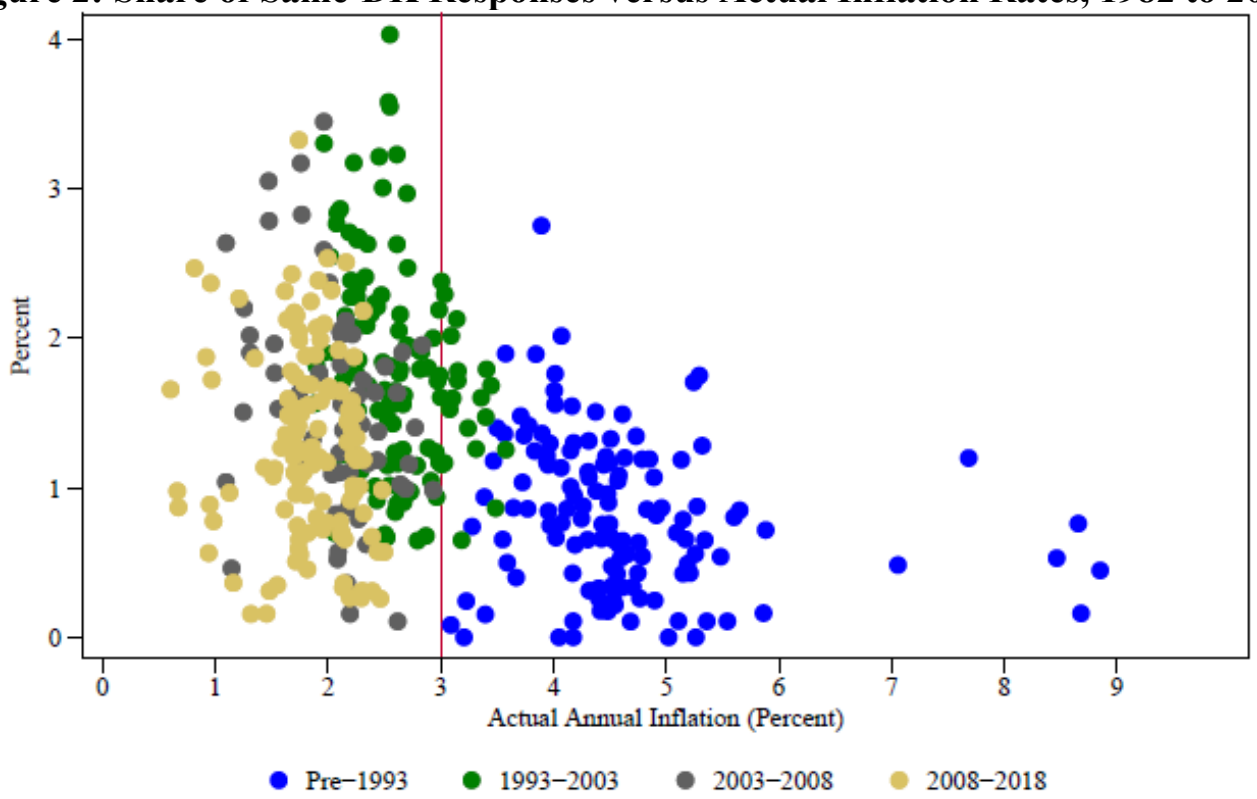

Sources: Bureau of Labor Statistics / University of Michigan's Surveys of Consumers.

Table 1: Same-DK Responses and Scaled Errors by Inflation Threshold

Panel A: Share of Same-DK Responses

\begin{tabular}{lccc}
\hline Dep. Var: Prob. Same DK & $(1)$ & $(2)$ & $(3)$ \\
High Inflation & $>2$ & $>3$ & $>4$ \\
\hline High Inflation & $-0.286^{* * *}$ & $-0.618^{* * *}$ & $-0.738^{* * *}$ \\
& $(0.080)$ & $(0.068)$ & $(0.076)$ \\
Constant & $1.530^{* * *}$ & $1.529^{* * *}$ & $1.489^{* * *}$ \\
& $(0.069)$ & $(0.040)$ & $(0.037)$ \\
\hline R-Squared & 0.03 & 0.16 & 0.18 \\
Adjusted R-Squared & 0.03 & 0.16 & 0.18 \\
Observations & 434 & 434 & 434 \\
Low Inflation Count & 110 & 285 & 333 \\
High Inflation Count & 324 & 149 & 101 \\
\hline
\end{tabular}

Standard errors in parentheses.

${ }^{*} p<0.10,{ }^{* *} p<0.05,{ }^{* * *} p<0.01$
Panel B: Mean Absolute Errors Scaled by Actual Inflation

\begin{tabular}{lccc}
\hline Dep. Var.: Error Share & $(1)$ & $(2)$ & $(3)$ \\
High Inflation & $>2$ & $>3$ & $>4$ \\
\hline High Inflation & $-0.800^{* * *}$ & $-0.631^{* * *}$ & $-0.593^{* * *}$ \\
& $(0.069)$ & $(0.058)$ & $(0.063)$ \\
Constant & $1.900^{* * *}$ & $1.537^{* * *}$ & $1.461^{* * *}$ \\
& $(0.062)$ & $(0.038)$ & $(0.036)$ \\
\hline R-Squared & 0.22 & 0.20 & 0.16 \\
Adjusted R-Squared & 0.22 & 0.20 & 0.15 \\
Observations & 473 & 473 & 473 \\
Low Inflation Count & 101 & 274 & 322 \\
High Inflation Count & 372 & 199 & 151 \\
\hline Standard errors in parentheses. & & \\
${ }^{*} p<0.10,{ }^{* *} p<0.05,{ }^{* * *} p<0.01$ & &
\end{tabular}


Table 2: Median Inflation Expectations Model, January 1978 to April 2018

\begin{tabular}{|c|c|c|c|c|c|c|c|c|c|}
\hline \multirow{3}{*}{ Dep. Var:: Inflation Expectations } & \multicolumn{3}{|c|}{ High Inf Above 2} & \multicolumn{3}{|c|}{ High Inf Above 3} & \multicolumn{3}{|c|}{ High Inf Above 4} \\
\hline & (1) & (2) & (3) & (4) & (5) & (6) & (7) & (8) & (9) \\
\hline & High Inf & Low Inf & Combined & High Inf & Low Inf & Combined & High Inf & Low Inf & Combined \\
\hline \multirow[t]{2}{*}{ Correction Term } & $-0.484 * * *$ & -0.030 & -0.030 & $-0.832 \cdots$ & -0.029 & -0.029 & $-0.957^{\cdots \cdots}$ & -0.029 & -0.029 \\
\hline & $(0.135)$ & $(0.179)$ & $(0.178)$ & $(0.169)$ & $(0.141)$ & $(0.141)$ & $(0.179)$ & $(0.070)$ & $(0.070)$ \\
\hline \multirow[t]{2}{*}{ Previous Year's Expectation } & $0.672^{* * *}$ & 0.054 & 0.054 & $0.696^{* \cdots}$ & 0.220 & 0.220 & $0.711^{\cdots}$ & $0.212^{* *}$ & $0.212^{* *}$ \\
\hline & $(0.086)$ & $(0.213)$ & $(0.212)$ & $(0.076)$ & $(0.154)$ & $(0.154)$ & $(0.073)$ & $(0.087)$ & $(0.087)$ \\
\hline \multirow[t]{2}{*}{ High Inflation Dummy } & & & $-1.774^{* * *}$ & & & $-2.025^{* * *}$ & & & $-2.383^{\cdots *}$ \\
\hline & & & $(0.518)$ & & & $(0.475)$ & & & $(0.438)$ \\
\hline \multirow[t]{2}{*}{ Interaction with Correction } & & & $-0.454^{* *}$ & & & $-0.802^{* * *}$ & & & $-0.928 \cdots$ \\
\hline & & & $(0.227)$ & & & $(0.220)$ & & & $(0.192)$ \\
\hline Interaction with Previous Year's Expectation & & & $0.619^{\cdots}$ & & & $0.476^{* * *}$ & & & $0.499 * *$ \\
\hline & & & $(0.228)$ & & & $(0.172)$ & & & $(0.114)$ \\
\hline \multirow[t]{2}{*}{ Constant } & $0.994^{* * *}$ & $2.767^{\bullet \bullet}$ & $2.767^{\cdots *}$ & 0.281 & $2.306^{* * *}$ & $2.306^{* * *}$ & -0.050 & $2.333^{\cdots *}$ & $2.333^{* *}$ \\
\hline & $(0.276)$ & $(0.448)$ & $(0.444)$ & $(0.315)$ & $(0.358)$ & $(0.358)$ & $(0.361)$ & $(0.247)$ & $(0.248)$ \\
\hline R-Squared & .78 & 0 & .77 & .84 & .04 & .82 & .83 & .04 & .83 \\
\hline Adjusted R-Squared & .78 & 0 & .77 & .84 & .04 & .82 & .83 & .04 & .83 \\
\hline Observations & 362 & 110 & 472 & 187 & 285 & 472 & 139 & 333 & 472 \\
\hline
\end{tabular}

Newey-West heteroscedasticity and autocorrelation consistent standard errors in parentheses.

${ }^{*} p<0.10, * p<0.05, \cdots p<0.01$

Figure 3: U.S. Phillips Curve for 1958-1969 and 1995-2018
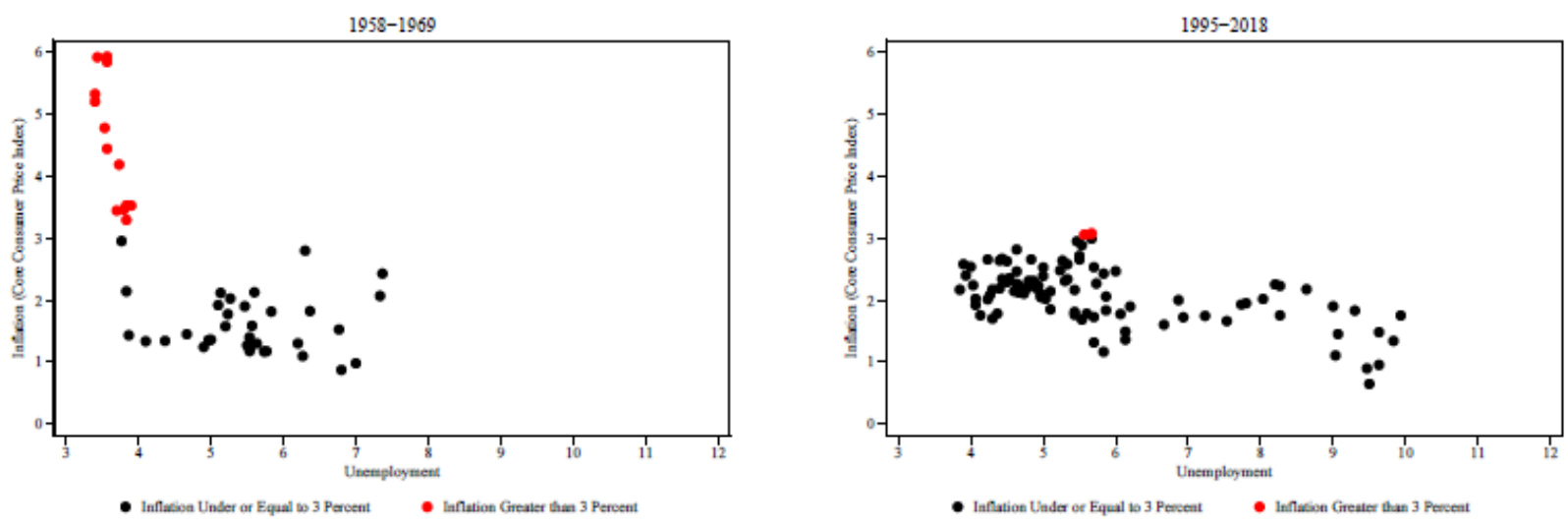

Source: Haver Analytics. 